influenced by them to take a keener interest in our school work. This subject of physical geography is a live one, needs only a little enthusiasm and tact to make it the most valuable of all the sciences. The writer would be pleased to hear from any one who has done real systematic work in this subject, and who has suggestions or criticisms to offer.

\title{
AN EXPERIMENTAL ILLUSTRATION OF OSMOTIC PRESSURE.
}

BY O. F. ADAMS.

Head of Department of Physics and Chemistry, Central High School, Detroil, Mich.

Doubtless many teachers of physies like myself have had much trouble in illustrating osmosis by the methods usually given in the textbooks and the following experiment may be of interest to them.

Acting upon a suggestion of Dr. L. Murbach, given in the November number of Schoor Science, page 300 , I secured a large, sound carrot. In the axis of this by means of a carpenter's bit I bored a hole about $2.5 \mathrm{~cm}$. in diameter and $10 \mathrm{~cm}$. deep. I also peeled the carrot up to its crown. The hole was then nearly filled with sugar and water added to within a centimeter of the top. To close the hole a two-hole rubber stopper was used, in one hole of which was inserted a piece of barometer tubing about $2 \mathrm{~m}$. long and having a bore of about $1.5 \mathrm{~mm}$. After the stopper with the long tube was firmly driven into the top of the carrot, the other hole in the stopper was closed by a glass plug. It was then supported, by means of a clamp, on a ring stand in a beaker of water so that all but the top was immersed in the liquid. Two hours and a half after it was first set up the liquid had reached the top of the tube. At four o'clock in the afternoon the carrot was again filled and set up and the glass tube lengthened by con. 
necting another glass tube to it by means of a piece of rubber tabing. The bore of the upper tube was larger than the lower one and hence the rate at which the liquid rose through it was much less than in the lower one. The top of the tube was $308 \mathrm{~cm}$. above the water in the beaker. At 8 o'clock the next morning the tube was full and the current in it was still upward, while on the outside of it there was a trail of thick syrup, showing that it had run over during the night. The liquid forced up the tube was a thick syrup with a density possibly of $2 \mathrm{~g}$. per $\mathrm{c}$ c., hence the pressure here shown is about twice as great as it would have been if pure water had been raised to the same height, but only a fraction of the total osmotic pressure such a solution of sugar is capable of producing.

Perhaps some of the readers of Sohool ScIence may be sufficiently interested in this experiment to test its possibilities still further. I have tried other vegetables besides the carrot but none of thern seemed to be so well adapted for the purpose as that.

\title{
AN EXPERIMENT IN RESOLUTION OF FORCES.
}

\author{
BY E. O. WOODRUFF.
}

Instructor in Physics, La Grange (IIt) High School.

Composition and resolution of forces seems to be a part of physics that puzzles the majority of pupils. Their bewildered state of mind is probably due largely to their lack of constructive imagination. Among the other functions of the high school laboratory the development of a constructive imagination seems to be one of the most important. Hence the more intimately we can deal in the laboratory with difficult questions that involve this faculty the better. The usual experiments with three spring balances cover the questions in composition of forces satisfactorily. But so far no experiment seems to bring out the points involved in the resolution of a force. Of course every case of static composition can and should be interpreted also as a case in resolution. Still even this will leave something to be desired. An experiment where the question of resolution is the leading question would seem to be 